\title{
Emotions in Learning at Work: a Literature Review
}

\section{Päivi Hökkä ${ }^{1}$ (D) Katja Vähäsantanen ${ }^{1} \cdot$ Susanna Paloniemi ${ }^{1}$}

Received: 23 November 2018 / Accepted: 28 May 2019 / Published online: 12 June 2019

(C) The Author(s) 2019

\begin{abstract}
The research elaborating emotions in organizational settings has increased considerably in recent years. However, we lack a comprehensive understanding of the role of emotions in learning at work. This review aimed to elaborate how emotions and learning are understood in the field of workplace studies, and how emotions and learning at work are related. For the review, 31 scientific articles were selected and analysed. We found that emotions and learning were understood in a range of ways in the articles. Emotions were mainly defined as emotional experiences and responses, and learning at work mainly referred to learning through participatory practices. In addition, the review illustrates the relationship between emotions and learning at work. Most of the studies focused on the active role of emotions in supporting and/or hindering learning at work, but some indicated the contrary direction of influence, with emotions at work being influenced by learning. The review further illustrates trends and gaps in this research field, and suggests some theoretical underpinnings, with recommendations for future research.
\end{abstract}

Keywords Emotions $\cdot$ Learning at work $\cdot$ Review $\cdot$ Workplace studies

\section{Introduction}

The significance of emotions in learning and working has gained considerable attention in recent years. Emotions and learning have been of particular interest in studies on school learning, teachers, and students (e.g. Becker et al. 2014; Uitto et al. 2015).

\section{Päivi Hökkä}

paivi.hokka@jyu.fi

Katja Vähäsantanen

katja.vahasantanen@jyu.fi

Susanna Paloniemi

susanna.paloniemi@jyu.fi

1 Department of Education, University of Jyväskylä, P.O. Box 35 (RUU D422), 40014 Jyväskylä, Finland 
Furthermore, the interest in emotions and learning has increased in the field of workplace studies. However, up until a few decades ago, workplaces were seen primarily as rational domains demanding an emotionally neutral performance from employees and leaders. This paradigm was based on the assumption that human behaviour in organisational settings follows rational rules and is mainly guided by plans and calculations based on cognitive processes (Ashkanasy et al. 2000; Gabriel and Griffiths 2002). However, there has been a paradigm shift in understanding the significance of emotions in organisational settings and elsewhere. Recent research has convincingly shown that emotions play a significant role in workplaces, organisational behaviour, and leadership (e.g. Gooty et al. 2010; Riforgiate and Komarova 2017). There is also growing interest in stress and well-being at work in the field of work and organisation psychology (e.g. Siltaloppi et al. 2009).

Despite the greater focus on emotions at work, only a few studies have investigated emotional aspects as they pertain to the learning of employees and leaders in working life. Thus, one might say that in the field of learning at work, the emotional dimension has been neglected. The most prominent exception is in the special issue of Journal of Workplace Learning, guest-edited by Benozzo and Colley (2012), which addresses emotions and learning in the workplace. In their guest editorial, Benozzo and Colley present an understanding of emotion and learning as two social processes that are inseparably intertwined and interdependent. This approach challenges scholars to thoroughly investigate how emotions and learning in the workplace are related. Along similar lines, Antonacopoulou and Gabriel (2001) argue that emotion and learning constitute highly interrelated, interactive, and interdependent phenomena in organisational contexts. They also argue that the interface between them should be a focus of study.

Although some recent studies have considered adults and their emotions in learning at work, we lack a comprehensive elaboration of studies on the relationship between emotions and learning at work. To consider what kinds of studies should be undertaken in the future, we need to review what has been done so far. Thus, our main purpose is to analyse the diversity of research in the field, illustrate the trends and gaps, and suggest future directions for researching emotions in learning at work.

Below, we present our main concepts related to emotions and learning at work. We describe the procedures used to select and analyse the articles included in this review, and we introduce what appear to be the striking details of the selected articles. In particular, we address the relationship between emotions and learning at work as revealed in articles that consider these phenomena in workplace contexts. We then present our findings and discuss the implications before concluding with recommendations for future theoretical and empirical studies.

\section{Theoretical Considerations: Emotions and Learning at Work}

\section{Emotions in Workplaces}

There is no agreement on what constitutes an emotion, how emotions should be studied, or how the implications for the study of emotions should be implemented in workplaces (e.g. Antonacopoulou and Gabriel 2001). Indeed, there is considerable 
debate on the nature and ontology of emotions. Broadly speaking, the understanding of emotions can be divided into two main schools of thought: understanding emotions through sociological or socio-cultural theories or understanding them as definable via psychological theories. In psychological theories, the understanding of emotion as primarily an individual experience and essentially intrapsychic phenomenon is the most established one. Cognitive emotion theory highlights the meanings of beliefs as major antecedents of emotions. This idea is emphasised especially in appraisal theory (Scherer 1999), which understands emotions as resulting from how the individual believes the world to be and what implications events have (Frijda et al. 2000). Under the broad umbrella of the psychodynamic approach, emotions are considered to be individual and subjective feelings that may lead to different behavioural manifestations or reactions. Emotions can, thus, be understood as discrete, referring here to universally shared, basic emotions, such as anger or joy, which are thought to correspond to specific facial expressions (Damasio 1999; Ekman 2016). Another psychodynamic approach considers emotions via the dimensions of pleasant/unpleasant and low/high intensity (e.g. Ekman 2016; Harmon-Jones et al. 2016). This leads to a characterisation of emotions in terms of valence, referring to subjective feelings of pleasantness or unpleasantness, and arousal, referring to the subjective state of feeling either activated or deactivated (Feldman Barrett 1998).

Sociological and socio-cultural approaches argue that understanding emotion merely as an individual experience ignores the meaning of particular social and cultural contexts and the interpersonal, communicative function of emotions (Parkinson et al. 2005). Thus, according to socially oriented views, emotions are not only as phenomena that exist in the mind but as entities that shape and structure social interaction and its consequences (Hareli et al. 2008). The central idea is that emotional expressions are dependent on learned rules that are socially and culturally constituted (Zembylas 2007). Emotions can also be understood as culturally coded social entities, referring to socially produced categories and concepts that have the weight of tradition and everyday experience behind them (Russell 2003). Emotions are then viewed as active processes that shape everyday practices, interactions, and their consequences, for example, in workplace contexts.

In the field of organisation and workplace studies, scholars have approached emotions through psychological and sociological lenses. In this field, emotions have often been approached via the concepts of emotional intelligence and emotional labour. Emotional intelligence refers to the extent to which one can monitor feelings and direct one's own thinking and actions accordingly (Goleman 1995; Salovey and Mayer 1990). This encompasses the ability to recognise and understand emotions in oneself and others and to use this information to guide decision-making and actions (Salovey and Mayer 1990). Emotional labour (Hochschild 1983) encompasses the study of (i) how displays of emotion, as part of individuals' work roles, are used to influence others to accomplish organisational goals, such as increased customer satisfaction (e.g. Sutton and Rafaeli 1988), or (ii) how organisationally acceptable emotions can be generated (e.g. Grandey 2003). In general, emotional labour means that employees are asked to regulate or manage their emotional behaviour in terms of both the content and range of their emotions and the intensity and duration of their emotions (Morris and Feldman 1997). Thus, the term is applicable to situations where employees are required to display emotions that differ from the ones that they actually feel (Hochschild 1979). 
The concepts of emotional labour and emotion work are sometimes used as synonyms or interchangeably to refer to the same idea. However, they have their own meanings and conceptualisations, the main difference being that "work" refers broadly to situations within everyday life, while "labour" refers especially to paid work and includes managing or regulating emotions to get a salary (Hochschild 1983; Benozzo and Colley 2012). In addition, the concept of emotion regulation is seen as being closely related to emotional labour. Gross (1998, p. 275) defines emotion regulation as 'the processes by which individuals influence which emotions they have, when they have them, and how they experience and express these emotions'. Emotion regulation can be implemented as antecedent-focused or response-focused, the former pointing to how one can regulate the precursors of emotion and the latter how one can modify the observable signs of emotions (Grandey 2000).

Overall, one can say that the conceptual discussion and empirical studies (notably in the fields of organisational and workplace studies) have conceptualised emotions in a range of ways, but that emotions, on the whole, have tended to be seen as socially constructed and regulated. In this review, we take a holistic stance because our prime interest is in how emotions are understood and described in studies on learning at work. It should be noted here that we also acknowledge the relevance of concepts like affect, mood, and feelings in organisation studies (e.g. Fotaki et al. 2017); however, we distinguish between these closely related concepts and emotions, and for the sake of clarity, we view it as more fruitful to focus purely on emotions in this article.

\section{Learning at Work}

Research on learning at work has evolved in many directions and over many disciplines in recent decades. Thus, there is no general agreement on what learning at work truly is (e.g. Manuti et al. 2015; Goller and Paloniemi 2017). Traditionally, following the metaphors of learning as knowledge acquisition and as knowledge construction (see e.g. Lehtinen et al. 2014), learning at work has been understood mainly as a cognitive and/or behavioural process manifested through sense-making, critical reflection, acquiring new knowledge and competencies or updating skills (e.g. Eraut 2011). In recent research, self-regulated learning and self-directedness have been of growing interest in relation to learning at work (e.g. Bell 2017; Raemdonck et al. 2017). These studies emphasise the employee's active role in goal-setting, the choice and application of learning strategies and the critical assessment of learning when participating in certain learning activities at work (e.g. training courses, knowledge sharing).

In her review, Tynjälä (2013) provides a broader perspective on learning at work by describing six main research lines in the field of workplace learning: (i) the nature of workplace learning, (ii) identity and agency, (iii) professional expertise, (iv) competence development in vocational education and training and in higher education, (v) communities of practice, and (vi) organisational learning. Each research line has a unique origin, either from a disciplinary background or from the context within which work-related learning takes place, with 'context' encompassing the learning goals.

In recent years, learning at work has often been understood as practice-based professional development, which occurs in natural work-related contexts (e.g. Eraut 2011; Billett et al. 2014). Such a view emphasises the informal nature of learning, with learning understood as engaging in everyday work practices. It focuses on a close 
relation with everyday work tasks and on the experiential development of professional expertise through social interaction and relationships, plus individual reflection (e.g. Valleala et al. 2015; Goller et al. 2018). Consequently, workplace learning encompasses not only the learning of knowledge and skills but also the implicit and tacit learning of work practices and workplace cultures (Eraut 2004). This occurs particularly though participation in everyday work practices and communities (e.g. Billett 2011). For most studies adopting the practice-based approach, the focus in investigating learning lies merely in the learning processes instead of specific learning outcomes.

Furthermore, understandings of learning at work have relied on socio-cultural theory, which sees learning as primarily a community-based phenomenon falling into the participation metaphor of learning (see e.g. Lehtinen et al. 2014). There are two main traditions within the socio-cultural approach. One emphasises social and material resources and affordances in learning. Here, the community is seen as determining the conditions for learning; it forms a social structure in which relationships with others and other communities play a crucial role (Lave and Wenger 1991). Within this tradition, there is also a branch termed activity theory, which considers the relationship between mind, culture, and context. It emphasises the interaction between employees and cultural tools (such as language, physical artefacts, norms, and rules) as mediating learning at work (e.g. Engeström et al. 1999). The second important tradition within socio-cultural theory gives less weight to the notion of individuals and learning as subjugated by social and material contexts; instead, learning at work is seen as linked to the role of the individual in relation to professional backgrounds, experiences, and agency (Billett 2011).

In the most recent studies, learning at work is conceptualised as the (re-)negotiation of professional identity (Eteläpelto et al. 2014). Within these studies, learning at work may indeed be understood as the development of individual and collective work practices; however, it is also strongly linked to the development of employees' professional identities, skills, and knowledge. According to Vähäsantanen et al. (2017), professional identity learning covers processes by which professionals become aware, reflect on, and process their professional commitments, values, and careers while considering their strengths and weaknesses at work. Overall, there seems to be a tendency towards a more comprehensive approach within which professional identities, agency, and work practices are viewed as central to the processes of learning at work, rather than learning being seen merely as the development of professional knowledge and skills (see also Tynjälä 2013; Goller and Paloniemi 2017).

Thus, the arguments published thus far show no consensus on a theory of learning at work. Even though the established acquisition, participation, and knowledge-creation metaphors of learning research (see e.g. Lehtinen et al. 2014) are not to be understood as mutually exclusive, they do present different theoretical and methodological assumptions regarding the nature of learning. Traditionally, learning at work has been understood largely in terms of cognitive processes, but recently it has come to encompass the development of professional identities and work practices (e.g. Vähäsantanen 2015). Despite the emergence of various notions of learning at work, only a few studies have specifically addressed the role of emotions in learning and development in work-related contexts. Therefore, this review focuses on articles which, to a greater or lesser degree, take into account the possible relevance of emotions to learning at work. 


\section{Aim and Research Questions}

The main purpose of the present study was to elaborate researchers' views on emotions in relation to learning at work and determine how emotions and learning at work are understood in the field of workplace studies. Thus, our research questions were as follows:

(1) How are emotions understood?

(2) How is learning at work understood?

(3) What kinds of relationships between emotions and learning at work can be identified?

\section{Methods}

\section{Literature Search and Article Selection Criteria}

During the first stage of collecting review data, we investigated 14 peer-reviewed scientific journals focusing on professional and adult learning. The journals are presented in more detail in Table 4 (see Appendix). These journals were chosen in line with purposive sampling, with a focus on journals elaborating issues in workplace learning and human development addressing explicitly the issues of learning at work among employees and in work environments in different ways. At this point, we were especially interested in workplace learning journals. Thus, we excluded journals, for example, from the psychological and management fields and journals on vocational education and training whose scope was notably related to students' learning and education systems. Furthermore, we excluded all teacher and teacher education journals because these journals had a very high number of studies and reviews focusing on teachers' emotions and learning (e.g. Uitto et al. 2015), the inclusion of which seemed likely to distort the review. The journal selection criteria also required that all journals be peer-reviewed and international in scope. We further limited our review to papers that had been published between 2000 and 2017.

In reviewing these journals, we sought articles elaborating emotions and learning among adults, employees, leaders, and managers. Consequently, we selected articles containing the following keywords (i) emotions and (ii) learning at/through/in work, professional learning, adult learning, workplace learning, work-related learning, professional development, identity construction, and identity negotiation or identity development. In evaluating the eligibility of the articles for inclusion in the review, we were only interested in those elaborating both emotions and learning at work. Thus, articles that did not explicitly address both learning at work and emotions were excluded. This meant, for example, that articles discussing emotions in workplace contexts in general, without any connection to learning at work, were omitted. Another group of studies that we excluded considered learning in formal schooling contexts (e.g. in vocational education or apprentice learning). The selection was based on the title, abstract, and keywords, and resulted in a list of 25 articles. However, as the data obtained in this way were likely to be incomplete, we extended our search to gain more comprehensive coverage of all relevant articles. 
During the second stage of data collection, we utilised the Google Scholar and ERIC databases to confirm and complement the review data collected during the first stage. In selecting appropriate articles for review, the same procedure, criteria, and keywords (emotions and learning at/through/in work, professional learning, adult learning, workplace learning, work-related learning, professional development, identity construction, identity negotiation, identity development) from the first stage were utilised. The ERIC search retrieved 299 publications. After critical evaluation, a Google Scholar search resulted in 18 new articles and another ERIC search resulted in 18 additional articles.

Thereafter, we examined the selected articles (now 61 in total) more critically. At this stage, we read all articles in depth, with selection taking place on the basis of the full texts. Out of these 61 articles, we selected 31 according to our prime rule - that we were only interested in articles elaborating both emotions and learning at work. However, despite excluding journals in the domains of (i) teaching and teacher education, (ii) management, and (iii) organisation studies during the first data gathering stage, we no longer excluded articles considering emotions and learning in these domains, provided we had obtained them through Google Scholar or ERIC, and provided they had been published in journals of workplace studies or journals closely connected to the field of workplace studies (e.g. Journal of Clinical Nursing).

There are a few limitations that should be acknowledged. One obvious limitation is that this review focused only on studies published in journals. Thus, it omitted texts in books, handbooks, compilations, and conference proceedings. Another limitation is that we excluded all articles prior to 2000. This was because we noticed, after a preliminary investigation, that empirical research on emotions in the domain of learning has mostly emerged in the present millennium. We also aimed to provide a perspective on emotions in learning at work on the basis of the most up-to-date publications.

\section{The Nature of the Selected Articles}

Most of the selected articles $(n=31)$ were published in the Journal of Workplace Learning $(n=9)$, and a few were published in Human Resource Development International $(n=3)$. The remaining articles were published in various other journals.

The articles selected for the review comprised theoretical papers $(n=5)$ and empirical papers $(n=26)$. Most of the empirical articles present a qualitative study investigating emotions and learning at work $(n=14)$. In these studies, the scholars mainly applied an interview research design or used various qualitative methods simultaneously (especially interviews combined with observations and documents). In the case of the three quantitative studies, the data were collected via questionnaires. Nine empirical studies further combined qualitative and quantitative methods, especially including qualitative interviews and quantitative questionnaires or qualitative self-reports together with quantitative questions. The article types are presented in detail in Table 5 (see Appendix).

As presented in Table 6 (see Appendix), most of the articles relate to the domains of teaching and science $(n=11)$. They cover a range of educational contexts, including primary and secondary schools, and further and higher education. Several studies were also conducted in the domain of healthcare and social work $(n=7)$; these studies cover many different professional groups encompassing nurses, physicians, therapists, youth workers, and managers. Some articles also concern the service sector $(n=4)$ and 
technology and industry $(n=4)$. In addition, theoretical articles were chosen that are not concerned with any specific domain, as well as empirical studies covering many domains simultaneously; these were placed in the category of "General or several domains" $(n=5)$.

\section{Analysing the Selected Articles}

Altogether, the final sample comprised 31 articles. To analyse the articles, we utilised the thematic review approach to reflect and synthesise the understandings of emotions and learning at work (Attride-Stirling 2001; Braun and Clarke 2006). We chose this approach due to its flexible and systematic nature in reflecting these multifaceted phenomena and the relationship between them. We collaborated closely and utilised researcher triangulation to increase the quality of the review (Hastings 2010). Here, it should be noted that the codes and categories were based on the perspectives and contents of the articles, but that the names attached to them reflected current understandings in the learning and emotions research. In this regard, our analysis was datadriven, but theoretically informed. To check the reliability of the coding procedure, we elaborated and explicated the initial coding frames and categories and defined the final categories. We used only the coding categories with $100 \%$ intercoder agreement (Schreier 2012).

First, each researcher analysed the articles individually. We utilised a data coding form to ensure consistency in the coding process. We extracted the following information from each study: (1) identification (i.e. authors, date of publication, journal), (2) methodology, (3) domain of the study, (4) understanding of emotions, and (5) understanding of learning at work. Subsequently, we discussed the articles and their contents and compared our individually produced codes and categories to arrive at a shared understanding of the phenomena under investigation.

After a close reading and rereading, our collective analysis produced four main emotion categories (emotional experiences, emotional responses, emotional intelligence, emotional labour) related to the first research question. These final categories were composed according to the following codes: Emotional experiences: emotional states, subjective feeling, individual feeling; Emotional responses: emotional responses, emotional reactions, managing emotion, emotional behaviour; Emotional intelligence: emotional intelligence; Emotional labour: emotional labour, emotional work.

Relating to the second research question, we identified four main categories related to learning at work (learning through participatory practices, cognitive learning, development of emotional skills, identity learning). Learning at work categories were composed as follows: Learning through participatory practices: participation in communities of practice, learning as a socialisation process, organisational learning, becoming a member, engaging in work practices; Cognitive learning: meaning-making, sense-making, critical reflection, problem-solving; Development of emotional skills: sense-making, reflection or self-regulation focused on emotional skills or competencies; Identity learning: identity work, identity negotiation, identity development.

Second, related to the third research question, we elaborated and compared the main categories to identify relationships between the two constituent phenomena (learning at work and emotions), paying attention to the kinds of emotion that were evident and the learning categories with which they interfaced. Having focused on the nature of this 
learning-emotion relationship, we identified two main obverse categories that appeared to illustrate this relationship - namely, how emotions influence learning at work and how learning influences emotions at work. Examining these categories in more detail, we identified three sub-categories illustrating how emotions influence learning and three sub-categories illustrating how learning influences emotions.

In practice, this second step means that we placed the articles under the first category illustrating how emotions support, trigger, and frame learning at work. As emotions seemed to influence three different forms of learning at work - namely, learning through participatory activities, cognitive learning, and identity learning - we identified these as three sub-categories of this main category. Respectively, we placed the articles under a second main category demonstrating how learning at work causes, brings about, and awakens emotions. As emotions were recognised as outcomes of three different forms of learning at work involving the development of emotional skills, learning through participatory practices, and cognitive learning, we used these as subcategories of this second main category.

Taking each research question in turn, we located each article within a single category on the basis of its overall thematic content. Although one could argue that this represents an over-simplification of complex phenomena, we saw it as useful for developing an overarching picture of the phenomena. It also appeared to be a practical procedure, even if it was difficult to place some articles in a single category given the complexity of the conceptualisations with which we were dealing. Thus, the composed categories are not 'pure' or clean-cut in nature; there are occasional overlaps between them.

Another challenge was that several articles encompassed fairly rare conceptualisations. Particularly in the case of the third research question, it should be noted that not all of the selected articles focus primarily on the relationship between learning at work and emotions. Thus, we faced occasional difficulties in analysing and categorising the articles according to the study questions, with authors' individual interpretations coming into play in some cases. There could be a degree of uncertainty, for example, regarding one's definition of learning at work as cognitive learning, the development of emotional skills, learning through participatory practices, or identity development.

During the final stage of the analysis, we counted the number of articles representing each category and sub-category. The Findings section presents the main findings, including the main categories related to all research questions and sub-categories related to the third research question, and the number of articles for each (sub-)category. Note that due to space considerations, we present the general characteristics of the articles, plus a few examples, rather than detailed descriptions of every article.

\section{The Understanding of Emotions}

We found that emotions were elaborated in the articles through the following theoretical lenses: (i) emotional experiences, (ii) emotional responses, (iii) emotional intelligence, and (iv) emotional labour. Table 1 summarises the four categories formed according the understanding of emotions.

Emotional experiences: Emotions are understood as emotional experiences in most of the reviewed papers (12 articles). In these papers, emotions are seen in general as 
subjective individual feelings within workplace practices that are connected to learning in some manner. In most of the papers, emotions are described as explicitly experienced emotions (most often negative emotions, such as fear and insecurity) connected to project failures (Shepherd et al. 2011), identity learning (Meijers 2002; Geijsel and Meijers 2005), critical action learning at work (Trehan and Rigg 2015), intercultural learning (Jokikokko and Uitto 2016), or well-being at work (Owen 2016). Two papers further stress negative emotions, such as anxiety, at the start of a new job (McNally et al. 2009) or emotional suffering amid tightened government policies in public service work (Colley 2012). Two papers by Rausch et al. (2015, 2017) describe emotions as emotional states; they refer to the common circumplex model of emotion (e.g. Russell 1980) and present the notions of valence, representing negative to positive emotions, and arousal, signifying the intensity of the experienced emotion. In the last two papers (Cripps Clark and Groves 2012; Rager 2013), emotions refer to emotional experiences, but the definition of emotions is somewhat unclear. All papers in the category of emotional experiences describe emotions slightly differently; however, they share the notion of emotions as primarily individually experienced feelings or emotional states that might lead to emotionally embedded reactions. Another common factor in the papers is that when explicitly describing the concept of emotion, all but two (Rausch et al. 2015; Owen 2016) focus on negative emotions, such as fear, anxiety, or insecurity. However, the papers in this category are not completely internally coherent in describing the concept of emotion. Emotional responses: Emotional responses represent the second most common category ( 9 articles). When emotions are seen as responses, they are mainly described as behaviours or as certain actions at work. Thus, although the emotions are based on internal emotional states, they are understood as responses or reactions, with a focus on observable actions. The particular focus of these papers is on issues accompanied by emotions, such as ethical competence, empowerment, and well-being. This category is the most uncertain one mainly due to the somewhat vague nature of the definitions in some of the papers. Some papers lack an explicit theoretical definition of emotions. In two papers, emotions as responses are seen via the need to manage them, with the main focus still being emotional responses and reactions. Falkenström et al. (2016) focus on rational emotions (i.e. reflective judgements based on both emotion and reason) in managing emotions, for example, in coping with uncertainty. Along similar lines, Nesbit (2012) understands emotions as emotional responses requiring emotional management, for example, in negative feedback situations. In two other papers, (discrete) emotions, such as anxiety, anger, and fear, are elaborated as emotional reactions. Jr Reio and Callahan (2004) understand emotions as enduring personality traits that express consistent patterns of reactions and behaviours in a variety of situations and contexts. Hareli et al. (2005) define emotions as powerful predictors of behaviour, elaborating them as social emotions, such as shame, guilt, and fear, in failure situations. The remaining five articles under this label do not explicitly define emotions via relevant literature. However, since they state their understanding of emotions as related to emotional responses or reactions, they are located in this category.

Emotional intelligence: Five of the reviewed articles elaborate emotions through the lens of emotional intelligence theory. This mostly relies on the seminal work of 
Salovey and Mayer (1990), who introduced the concept of emotional intelligence to the field, or the work of Goleman (1995), who popularised the construct. In these works, emotional intelligence is understood as involving individualised and interrelated social and emotional competencies that affect work effectiveness or performance. The studies utilise well-established measurements of socialemotional intelligence, such as the Bar-On EQ-inventory (Dolev and Leshem 2016) and the WLEI scale (Pradhan et al. 2017). Using these means, they investigate the four dimensions of EI (emotions of the self and others, emotionappraisal dimensions, the use of emotions, and emotion regulation) proposed by Wong and Law (2002). The concept of EI is also used more broadly to indicate general emotional abilities and competencies - qualities seen as valuable in the fields of nursing or management. Berg and Karlsen (2012) describe EI as a tool for managers to enhance their self-management skills, while Clarke (2007) sees it in terms of emotional abilities, such as managing one's own feelings in a hospice (terminal care) context, and Bailey et al. (2011) deems it an end product developed through emotional labour in emergency work. Each of the latter three studies refers to Goleman's (1995) work and thus relies more or less explicitly on the idea of EI as comprising four main components: self-awareness, self-management, social awareness (empathy), and relationship management (collaboration).

Emotional labour: Three studies elaborate emotions via the notion of emotional labour (Seymour and Sandiford 2005; Jakhelln 2010; Webb 2012). All three stress the importance of emotional rules in their understanding of emotions. Emotional rules are seen as appropriate and conventional emotional displays in a given situation or event, occurring within certain sociocultural contexts, for example, in teaching or customer service. Shan (2012) and Mirchandani (2012) employ the concept of emotion work to understand the concept of emotion. Mirchandani (2012) understands emotion work as (i) managing self-feeling, (ii) managing others to feel a certain way, and (iii) giving meaning and definition to one's own work. These five studies examine emotions in organisational contexts, making the border between the concepts of emotion work and emotional labour unclear (in terms of 'labour' referring to paid work and 'work' referring to everyday contexts outside of one's work). For example, Mirchandani (2012) justifies using the broader term 'emotion work' by arguing that it is often impossible to separate paid and unpaid feeling work in relation to training and learning at work. In this review, we are aware that the terms emotional labour and emotional work have slightly different connotations. However, for the sake of simplicity, we use the term emotional labour as the label for this category.

\section{The Understanding of Learning at Work}

The analysis revealed that learning at work can be understood as (i) learning through participatory practices, (ii) cognitive learning, (iii) the development of emotional skills, and (iv) identity learning. Table 2 summarises the four categories formed according to the definition of learning at work provided in the articles. 
Table 1 Understanding of emotion in the reviewed articles $(n=31)$

\begin{tabular}{|c|c|c|}
\hline Emotional experiences & 12 & $\begin{array}{l}\text { Cripps Clark and Groves (2012); Colley (2012); Geijsel and Meijers (2005); } \\
\text { Jokikokko and Uitto (2016); McNally et al. (2009); Meijers (2002); } \\
\text { Owen (2016); Rager (2013); Rausch et al. (2015); Rausch et al. (2017); } \\
\text { Shepherd et al. (2011); Trehan and Rigg (2015) }\end{array}$ \\
\hline Emotional responses & 9 & $\begin{array}{l}\text { Falkenström et al. (2016); Hareli et al. (2005); Nesbit (2012); } \\
\text { Reio and Callahan (2004); Sargeant et al. (2008); Saunders (2012); } \\
\text { Sebrant (2008); Scott and Sutton (2008); Vince (2002) }\end{array}$ \\
\hline Emotional intelligence & 5 & $\begin{array}{l}\text { Bailey et al. (2011); Berg and Karlsen (2012); Clarke (2007); } \\
\text { Dolev and Leshem (2016); Pradhan et al. (2017) }\end{array}$ \\
\hline Emotional labour & 5 & $\begin{array}{l}\text { Jakhelln (2010); Mirchandani (2012); Seymour and Sandiford (2005); } \\
\text { Shan (2012); Webb (2012) }\end{array}$ \\
\hline
\end{tabular}

Learning through participatory practices: Most of the reviewed articles (12 articles) define learning more or less explicitly in terms of socio-cultural theory, stressing the importance of communities and organisations as contexts in which (and by which and for which) learning takes place. Six of these articles address what learning may actually mean in a work community. Thus, Pradhan et al. (2017) and Vince (2002) understand learning as organisational learning, emphasising intra- and interpersonal dynamics among organisation members and addressing their actions amid changing social, economic, and political contexts. For Owen (2016), Jr Reio and Callahan (2004), Seymour and Sandiford (2005), and Shan (2012), learning is a socialisation process by which one becomes a member of a certain work community, organisation, or professional group. In these four latter articles, learning is seen as 'fitting in' by participating in professional learning communities at work.

This category contains six other articles that view learning mainly as engaging in novel work practices. However, these six articles emphasise the role of practical activities in learning rather than viewing it as a socialisation process. These articles also see learning as involving new ways of working and as developing novel work practices. For example, Saunders (2012) defines teachers' work as requiring continuous reforms touching on their pedagogical and instructional practices. Thus, it demands the implementation of novel work practices acquired through learning at work.

Cognitive learning: Eight papers describe learning as primarily a matter of cognitive processes, such as sense-making; critical reflection on one's own perspectives, ideals, and values; and problem solving. Learning, then, is understood as a process of giving new meanings and acquiring novel ideals, ideas, and perspectives through rational reflection and reasoning. In other words, learning is described as a matter of changes in thinking and acting, realised through sense-making and reflection. Interestingly, half of the papers in this category elaborate learning in either error or failure situations (Hareli et al. 2005; Sargeant et al. 2008; Shepherd et al. 2011; Rausch et al. 2017). Most of the eight papers that see learning through a cognitive lens elaborate learning through individual reflection. However, some of them also stress collective aspects of learning. For example, Trehan and Rigg 
(2015) elaborate the notion of critical action learning at work and emphasise that in seeking to deepen critical thinking, the key processes involve both individual and collective reflection.

Development of emotional skills: Seven papers represent the development of emotional skills. They also highlight reflection, self-awareness, and sense-making, but their primary focus is on emotional skills and competencies. These papers understand learning as managing one's emotional reactions and enacting selfregulatory processes for development. All of these articles elaborate the learning that takes place in challenging human-centred work contexts, including terminal care or emergency nursing (Clarke 2007; Bailey et al. 2011), demanding customer service work (Mirchandani 2012), management (Berg and Karlsen 2012; Nesbit 2012; Falkenström et al. 2016), and teaching (Dolev and Leshem 2016). For example, Mirchandani (2012) focuses on communication skills training given to transnational call centre workers in India and stresses how demanding it is to develop emotional skills. The study shows how the workers were trained to communicate effectively through their emotion work; however, at the same time, they needed, on a more informal basis, to develop coping skills to face abusive customers and deal with customer aggression.

Identity learning: Four of the reviewed articles understand learning as identity learning. These papers emphasise learning as more than the acquisition of new knowledge and competencies, seeing it primarily an identity negotiation process. For example, McNally et al. (2009) describe learning as a transformative process by which one becomes a new person (in their case, a teacher). In fact, it should be noted that three of these papers that understand learning as identity development elaborate teachers' work and career learning. This reflects the fact that understanding workplace learning as identity development is a relatively new theoretical approach, and one that has been utilised, above all, in the educational field.

\section{The Relationships between Emotions and Learning at Work}

In papers touching on the relationship between emotions and learning, emotions tend to be addressed as just one aspect of learning in addition to other equally relevant factors (e.g. social dimensions and processes, intuitive aspects, rational aspects). However, in analysing the relationships between emotions and learning at work, we identified two main categories (Table 3). The first one, which was the more frequently identified category, illustrates how emotions influence (support and/or hinder) learning at work. The second category is concerned with the contrary direction of influence - that is, how learning influences emotions at work. These main categories are presented below in detail, indicating also how different learning categories (e.g. cognitive learning) can be seen as related in various ways to a range of emotion categories (e.g. emotional intelligence).

\section{Learning at Work as a Phenomenon Influenced by Emotions}

Most of the selected articles (21/31) elaborate the relationship between emotions and learning at work via how learning is influenced by emotions. The elaboration is 
Table 2 Understanding of learning in the reviewed articles $(n=31)$

\begin{tabular}{|c|c|c|}
\hline earning through participatory practices & 2 & $\begin{array}{l}\text { Colley (2012); Cripps Clark and Groves (2012); Owen (2016); } \\
\text { Pradhan et al. (2017); Reio and Callahan (2004); } \\
\text { Saunders (2012); Sebrant (2008); Seymour and } \\
\text { Sandiford (2005); Scott and Sutton (2008); Shan (2012); } \\
\text { Vince (2002); Webb (2012) }\end{array}$ \\
\hline Cognitive learning & 8 & $\begin{array}{l}\text { Hareli et al. (2005); Jokikokko and Uitto (2016); } \\
\text { Rager (2013); Rausch et al. (2017); Rausch et al. (2015); } \\
\text { Sargeant et al. (2008); Shepherd et al. (2011); } \\
\text { Trehan and Rigg (2015) }\end{array}$ \\
\hline Development of emotional skills & 7 & $\begin{array}{l}\text { Bailey et al. (2011); Berg and Karlsen (2012); Clarke (2007); } \\
\text { Dolev and Leshem (2016); Falkenström et al. (2016); } \\
\text { Mirchandani (2012); Nesbit (2012) }\end{array}$ \\
\hline Identity learning & 4 & $\begin{array}{l}\text { Geijsel and Meijers (2005); Jakhelln (2010); } \\
\text { McNally et al. (2009); Meijers (2002) }\end{array}$ \\
\hline
\end{tabular}

multidimensional, encompassing all categories of learning at work and emotions. However, in these articles, emotions are often described as emotional experiences and responses (17 papers); thus, the elaboration of emotional intelligence and labour is substantially narrower in scope.

Emotions Influencing Learning through Participatory Practices Altogether, 10 papers in this review details how learning (seen as a matter of participating in everyday practices in communities and organisations) is influenced by emotions. In this sub-

Table 3 Relationships between emotions and learning

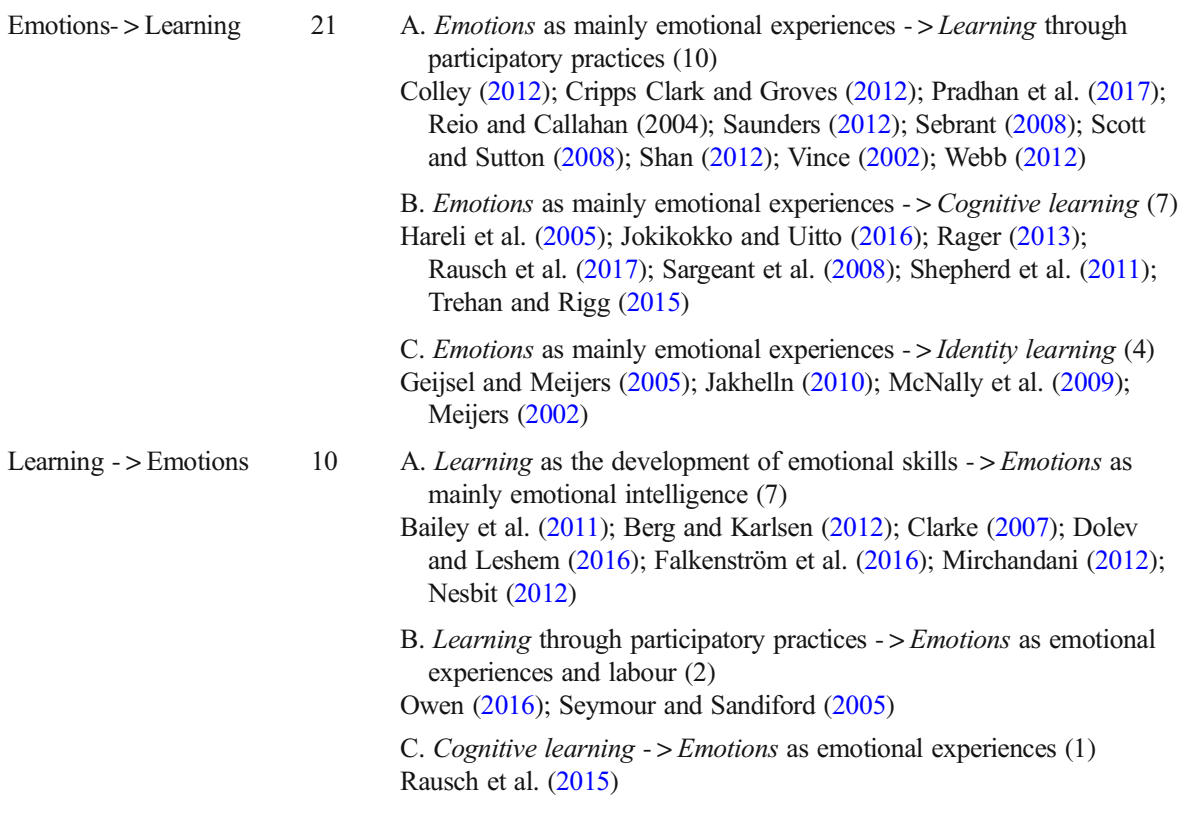


category, three articles deal with learning and emotions in the work of teachers (Scott and Sutton 2008; Cripps Clark and Groves 2012; Saunders 2012). Saunders (2012) examines teachers' professional development and emotions in the context of educational reform. She finds that the teachers' emotional responses directly influenced their use of new instructional processes. For example, teachers' experiences of anxiety and insecurity prevented them from trying out new pedagogical practices with their students. Colley (2012) and Sebrant (2008) examine emotions and learning in public sector work. Colley (2012) considers how recent austerity policies within public sector organisations caused emotional suffering among practitioners. This, in turn, seemed to obstruct workplace learning in various ways, causing, for example, 'not learning' at work. Pradhan et al. (2017), Jr Reio and Callahan (2004), Shan (2012), and Webb (2012) consider the importance of emotions in learning within everyday work practices (e.g. in the socialisation processes that occur in adjusting oneself to cultural practices), in the service industry and in engineering. Jr Reio and Callahan (2004) present evidence indicating that anxiety negatively influences socialisation-related learning, whereas anger has a positive influence on it. Most of the papers in this sub-category examine the challenging nature of emotions at work or emotions that are often labelled as negative, such as anxiety or envy. However, many papers (e.g. Jr Reio and Callahan 2004; Sebrant 2008; Colley 2012; Saunders 2012; Webb 2012) also underline the constructive and empowering aspects of negative emotions in workplace learning and the need for time and space for employees to share and discuss their emotions. They suggest that professional development processes could be built into work organisations by these means.

Emotions Influencing Cognitive Learning Seven papers illustrate how learning (understood as a cognitive phenomenon) is influenced by emotions. Within this sub-category, three studies concern the functioning of emotional experiences in failure or error situations (Hareli et al. 2005; Shepherd et al. 2011; Rausch et al. 2017). For example, Shepherd et al. (2011) find that in tensioned project-failure situations at work, persons who experience more negative emotions regarding failure have lower affective commitment to their organisation. Furthermore, coping with failure situations differs among organisation members; thus, learning from failure is not instantaneous or automatic but requires time and the individual ability to move beyond the failure. Sargeant et al. (2008) also discuss the consequences of negative emotions. They find that receiving negative feedback at work often evokes negative feelings. However, when this negative feedback is reflected on over a sufficient period, it can act as a learning experience and improve work performance. Jokikokko and Uitto (2016) share teachers' stories of their intercultural learning. Their results suggest that emotion, especially anger, can shake up teachers' values and lead to new perspectives and actions. Similarly, Trehan and Rigg (2015) make special mention of the power of anger in learning. In this sub-category, most of the studies outline the effects of negatively associated emotions on cognitive learning, with possibilities for achieving new perspectives or critical thinking at work.

Emotions Influencing Identity Learning All four papers in this sub-category elaborate how emotions that influence identity learning carry forward into teachers' work or career development (Meijers 2002; Geijsel and Meijers 2005; McNally et al. 2009; Jakhelln 2010). The papers share the finding that emotions are important in identity 
learning at the start of one's career and, further, that they constitute an important aspect of workplace learning in the course of one's career. These studies also stress that the role of emotions has been overlooked, for example, in studying schools as contexts for teacher learning and change. The evolving nature of these studies is also clarified through their methodologies; two are theoretical papers and two are qualitative studies. In his theoretical paper, Meijers (2002) argues that emotions can play a key role in identity-learning processes. The paper also presents a model for identity learning. It combines cognition and emotion in terms of meaning-giving and sense-making in learning. He argues that in both meaning-giving and sense-making processes, emotions should be valued, but treated with caution.

\section{Emotions Influenced by Learning at Work}

The number of articles exploring how emotions are influenced by learning was lower (10/31) than in the opposite direction of influence. Most of the articles in this category define emotions as emotional intelligence $(5 / 10)$. Furthermore, the elaboration of how emotions are influenced by learning at work is narrower than in the contrary case. Indeed, the issue of how emotions are influenced by identity learning is not explored at all. Most of the papers (7/10) examine how emotional skills influence emotions.

Learning as the Development of Emotional Skills Influencing Emotions In this subcategory, four papers (Clarke 2007; Bailey et al. 2011; Berg and Karlsen 2012; Dolev and Leshem 2016) explain how the learning of emotional skills is connected to emotional intelligence. Skills such as self-awareness and assertiveness are also referred to as emotional abilities. These skills or abilities are seen as crucial prerequisites for developing emotional intelligence.

In his study exploring emotional intelligence in healthcare, Clarke (2007) stresses the ability to manage emotions using one's emotions to facilitate thinking and decisionmaking. He further argues that in considering whether emotional intelligence can be developed, it is important to focus on particular emotional abilities rather than on the construct of emotional intelligence in its entirety. In general, in all of these papers, emotional intelligence is seen as inseparably connected to better work performance (e.g. in the nurse-patient relationship in healthcare). Falkenström et al. (2016) and Nesbit (2012) touch on the question of how the development of emotional skills influences emotional responses. Developing emotional skills is seen as important in managing emotional reactions, for example, in coping with insecurity at work.

Learning through Participatory Practices as a Factor Influencing Emotions Two studies were categorised as stressing learning in communities as a factor influencing emotions at work. The common feature in these papers is an emphasis on work communities as prerequisites and resources for learning the emotional rules of the workplace (Seymour and Sandiford 2005) or for supporting positive feelings and wellbeing at work (Owen 2016).

Cognitive Learning as a Factor Influencing Emotions Rausch et al. (2015) uncover how emotional experiences are influenced by problem-solving situations at work. Their 
results show that problem detection resulted in negative emotional states, such as nervousness and fear, but also positive emotional states, such as feeling motivated and glad. Somewhat surprisingly, their results also reveal that after detecting problems, experts were more likely than novices to report negative emotional states. This is explained by the experts' better understanding of the consequences of problems and by the novices having less responsibility for work processes.

\section{Discussion and Conclusion}

In selecting the articles for review, we observed that the role of emotions in learning at work is an underexplored phenomenon. The number of articles fitting the review criteria was fairly low despite the extensive coverage that we aimed for. Notably, appropriate articles were not available in some highly established workplace learning journals (e.g. Journal of Education and Work, Vocations and Learning). This in itself would suggest a need for more research on emotions in learning at work. Below, we sum up some of the main findings of the review and make recommendations for future studies and for practice.

\section{Understandings of Emotions and Learning at Work}

Emotions and learning are understood in a range of ways in the reviewed literature. Most of the articles $(n=21 / 31)$ understand emotions as emotional experiences and responses. The remaining articles elaborate emotions through emotional intelligence or emotional labour theory. By contrast, emotions have been frequently explored from the viewpoint of emotional labour and emotional intelligence in the field of organisational and management studies. Another point to note is that the reviewed articles seldom explicitly describe or contextualise emotions. This is especially the case when emotions are explored as experiences and reactions. In this sense, several articles are unclear as to the definition of emotion and the theoretical understanding of the concept. Uitto et al. (2015) make a similar point in their review of teachers' emotions and learning.

Regarding learning at work, the articles mostly understand learning at work as learning through participatory practices, suggesting that learning at work occurs via engagement in individual and collective work practices. This is in line with the current notion that learning at work takes place at work, through work, and for work (e.g. Billett 2011). At the same time, studies approaching learning at work in terms of cognitive processes of knowledge and skills acquisition and integration were also present in the review. It should be noted that these perspectives are not mutually exclusive (Lehtinen et al. 2014), but they do represent different research paradigms. For understanding learning at work, participatory practices can, and often are expected to, yield knowledge creation and innovation. Similarly, self-directedness at work is supposed to foster participation in (collective) appropriate learning activities in working contexts. However, our review shows that most the studies on learning and emotions relied on a socio-cultural approach to learning emphasising participatory practices over other approaches. Overall, the review illustrates that the understanding of learning at work has widened to include the development of professional identities and work 
practices (e.g. Eteläpelto et al. 2014). However, the reviewed articles suggest that the development of professional identity remains underexplored in the field of learning in the workplace, particularly regarding the emotional dimension. In addition, there is an apparent need to investigate professional identity development in a wider range of professions, given that the articles in this review elaborate identity learning purely in the context of education (teaching and counselling).

\section{The Relationship between Emotions and Learning at Work}

As emphasised by Antonacopoulou and Gabriel (2001) and Benozzo and Colley (2012), there is a need to better understand the interdependent phenomena of learning at work and emotions and to investigate the relationships in more detail. According to our data, some scholars have conducted diverse and multidimensional studies; nevertheless, the total number of studies remains relatively low. Most of the reviewed articles show that emotions influence (support and/or hinder) learning at work $(n=21)$. In these cases, emotions are mainly understood as emotional experiences and responses. In the remaining articles $(n=10)$, the findings indicate that learning at work influences emotions at work. In these articles, emotions are mainly elaborated through emotional intelligence theory, with emotional intelligence being seen as something that can be learned through developing one's emotional skills.

One general finding from the review is that most of the papers focus on emotions with negative associations. A similar trend has been seen in the field of organisation and management studies, in which the role of positive emotions has been underrated. In line with this, Ashkanasy (2003) notes that in organisation studies, the role of negative emotions has received more attention and has been found to be complex and ambiguous in explaining organisational behaviour. However, arguably, there is no justification for ignoring positive emotions in organisational settings and in learning at work, and these emotions deserve more research. Overall, in future studies, it would be important to widen the picture on the role of emotions in learning. As many of the articles in this review suggest, it is not the case that only positive emotions support learning or that negative emotions necessarily hinder it. Indeed, as Meijers (2002) indicates, within identity learning, emotions that are generally defined as negative (e.g. involving insecurity) can have positive outcomes for the individual.

\section{Future Research and Practical Implications}

Overall, we would suggest that the relationship between emotions and learning at work should be explored empirically and multidimensionally. Such an exploration should touch on the following:

- The roles of emotions that boost or hinder learning at work

- Elaboration of emotions that influence learning and those that are influenced by learning

- Development of emotional competencies within authentic contexts where learning occurs through intervention

- The complex relationships between positive and negative emotions and learning (involving, for example, the constructive nature of negatively associated emotions) 
In exploring the backgrounds of the selected articles, we noted a few trends regarding the domains and methodologies of the articles. The reviewed studies were mostly conducted in the domains of teaching and science, healthcare, and social work. This reflects research on learning at work more broadly because, traditionally, much of the research has been conducted on professionals in healthcare and education. However, several professional domains and contexts are absent in the selected articles (e.g. industry, high technology, and the private sector in general). In addition, the methods used in the studies were mainly qualitative. Accordingly, we see a need to utilise quantitative methods along with qualitative methods and to conduct more research outside of educational and healthcare organisations. Here, one can point to the rapid use of new technologies, artificial intelligence, and robotics - that is, post-human aspects of work (notably in the service sector, industry, and healthcare). This would imply a need to explore emotions and learning in digitalised work environments and those in which robots have been introduced. Here, it is also worth noting that almost all of the reviewed articles were conducted in western countries (European countries, the United States, Canada, and Australia), and most of them were conducted in a European context. This suggests that more research on emotions and learning is needed globally.

This review faced limitations, which were discussed in the Method section. First, one could evaluate the number of articles as low. It is also worth noting that the selection criteria for journals and articles might have excluded some relevant articles. The analysis process also included some challenges. For example, since emotions were not clearly and explicitly defined in each paper, the categorisation of emotions was based mainly on our interpretations instead of on the authors' clear definitions.

Despite the aforementioned limitations, the review was able to provide theoretical and practical implications on the role of emotions in learning at work. In theoretical terms, our review notably contributes to the discussion on the relationship between emotions and learning by illustrating how learning influences and is influenced by emotions. Consequently, it is possible to suggest that the relationship between emotions and learning can be recognised as reciprocal. The review also emphasised that both positive and negative emotions are meaningful from the viewpoint of learning at work. In terms of the practical implications of the review for educating people working in professional learning and human resource development (HRD), we want to highlight that it is pivotal to train them (i) to recognise the role of emotions in learning and development processes and (ii) to support employees in learning about their emotions and in utilising them in learning and working processes. Therefore, we need to focus more on the role of emotions in such processes to elaborate and support learning in different work contexts.

In conclusion, we would argue that in workplace studies, the role of emotions has mainly been neglected, given the more general focus on rational and behavioural aspects in learning in workplaces. Studies in other fields (e.g. organisation, management, and teacher studies) have shown the crucial role of emotions in work contexts and in learning. To widen the picture on how learning at work takes place, we see a need for robust studies (both quantitative and qualitative) elaborating the relationship between emotions and learning at work. Furthermore, at a time when measurement technology, for example, relating to physiological data, has taken huge developmental steps, one can look forward to research designs combining real-time measurements with self-report data in studies on emotions and learning in the workplace (cf. Eteläpelto et al. 2018). Indeed, there is growing interest in studies considering, for 
example, artificial intelligence and learning, which gathers both physiological and behavioural data about emotion. Thus, there is also a need for better empirical grounding in terms of how emotions are understood and what indicators of emotions are utilised in respect of learning.

Acknowledgements We would like to thank Merianna Rossi for her help with the early version of the paper. This research was supported by the Academy of Finland [Grant number 288925, The Role of Emotions in Agentic Learning at Work].

Funding Information Open access funding provided by University of Jyväskylä (JYU).

\section{APPENDIX}

Table 4 The fourteen peer-reviewed scientific journals selected for the review

Adult Learning

Australian Journal of Adult learning

European Journal of Education of Adults

International Journal of Human Resources Development and Management

Journal of Education and Work

Journal of Workplace Learning

Human Resource Development International

Human Resource Development Review

New Directions for Adult and Continuing Education

New Horizons in Adult Education and Human Resource Development

Professional Development in Education

Studies in Continuing Education

Studies in the Education of Adults

Vocations and Learning

Table 5 The articles selected, by methodology applied

Theoretical articles $\quad 5$ Geijsel and Meijers (2005); Meijers (2002); Nesbit (2012); Rager (2013); Vince (2002)

Empirical articles: Qualitative studies (14)
Interviews
8 Clarke (2007); Colley (2012); Falkenström et al. (2016); Jokikokko and Uitto (2016); McNally et al. (2009); Mirchandani (2012); Sargeant et al. (2008); Shan (2012)
Multimethod qualitative studies
6 Cripps Clark and Groves (2012); Jakhelln (2010); Sebrant (2008); Bailey et al. (2011); Seymour and Sandiford (2005); Trehan and Rigg (2015)
Empirical articles: Quantitative
3 Pradhan et al. (2017); Reio and Callahan (2004); studies Shepherd et al. (2011) 
Table 5 (continued)

\begin{tabular}{lcl}
\hline Empirical articles: Mixed & Berg and Karlsen (2012); Dolev and Leshem (2016); \\
method studies & Hareli et al. (2005); Owen (2016); Rausch et al. (2017); \\
& Rausch et al. (2015); Saunders (2012); Scott and Sutton (2008); \\
& Webb (2012)
\end{tabular}

Table 6 Overview of the studies in different domains

\begin{tabular}{|c|c|c|}
\hline Teaching and science & 11 & $\begin{array}{l}\text { Cripps Clark and Groves (2012); Dolev and Leshem (2016); Geijsel and } \\
\text { Meijers (2005); Jakhelln (2010); Jokikokko and Uitto (2016); } \\
\text { McNally et al. (2009); Owen (2016); Saunders (2012); Scott and } \\
\text { Sutton (2008); Shepherd et al. (2011); Trehan and Rigg (2015) }\end{array}$ \\
\hline Healthcare and social work & 7 & $\begin{array}{l}\text { Bailey et al. (2011); Clarke (2007); Colley (2012); } \\
\text { Falkenström et al. (2016); Rager (2013); Sargeant et al. (2008); } \\
\text { Sebrant (2008) }\end{array}$ \\
\hline Service sector & 4 & $\begin{array}{l}\text { Mirchandani (2012); Reio and Callahan (2004); Seymour and } \\
\text { Sandiford (2005); Webb (2012) }\end{array}$ \\
\hline Technology and industry & 4 & $\begin{array}{l}\text { Pradhan et al. (2017); Rausch et al. (2017); Rausch et al. (2015); } \\
\text { Shan (2012) }\end{array}$ \\
\hline General or several domains & 5 & $\begin{array}{l}\text { Berg and Karlsen (2012); Hareli et al. (2005); Meijers (2002); } \\
\text { Nesbit (2012); Vince (2002) }\end{array}$ \\
\hline
\end{tabular}

Open Access This article is distributed under the terms of the Creative Commons Attribution 4.0 International License (http://creativecommons.org/licenses/by/4.0/), which permits unrestricted use, distribution, and reproduction in any medium, provided you give appropriate credit to the original author(s) and the source, provide a link to the Creative Commons license, and indicate if changes were made.

\section{References}

Antonacopoulou, E. P., \& Gabriel, Y. (2001). Emotion, learning and organizational change: Towards an integration of psychoanalytic and other perspectives. Journal of Organizational Change Management, 14(5), 435-451.

Ashkanasy, N. M. (2003). Emotions in organizations: A multi-level perspective. Multi-level issues in organizational behaviour and strategy. Research in multi-level issues, 2, 9-54.

Ashkanasy, N. M., Härtel, C. E. J., \& Zerbe, W. J. (2000). Emotions in the workplace: Research, theory and practice. In N. M. Ashkanasy, C. E. J. Härtel, \& W. J. Zerbe (Eds.), Emotions in the workplace: Research, theory and practice (pp. 3-18). Westport: Quorum Books.

Attride-Stirling, J. (2001). Thematic networks: An analytic tool for qualitative research. Qualitative Research, 1(3), 385-405.

Bailey, C., Murphy, R., \& Prorock, D. (2011). Professional tears: Developing emotional intelligence around death and dying in emergency work. Journal of Clinical Nursing, 20(23-24), 2264-3372.

Becker, E. S., Goetz, T., Morger, V., \& Ranellucci, J. (2014). The importance of teachers' emotions and instructional behavior for their students' emotions - an experience sampling analysis. Teaching and Teacher Education, 43, 15-26.

Bell, B. S. (2017). Strategies for supporting self-regulation during self-directed learning in the workplace. In R. A. Noe \& J. E. Ellingson (Eds.), Autonomous learning in the workplace (pp. 117-134). New York: Routledge.

Benozzo, A., \& Colley, H. (2012). Emotion and learning in the workplace: Critical perspectives. Journal of Workplace Learning, 24(5), 304-316. 
Berg, M. E., \& Karlsen, J. T. (2012). An evaluation of management training and coaching. Journal of Workplace Learning, 24(3), 177-199.

Billett, S. (2011). Subjectivity, self and personal agency in learning through and for work. In M. Malloch, L. Cairns, L. Evans, \& B. O'Connor (Eds.), SAGE handbook of workplace learning (pp. 60-72). London: Sage.

Billett, S., Harteis, C., \& Gruber, H. (Eds.) (2014). International handbook of research in professional and practice-based learning. Springer international handbooks of education. Vol. 1. Dordrecht: Springer.

Braun, V., \& Clarke, V. (2006). Using thematic analysis in psychology. Qualitative Research in Psychology, 3, 77-101.

Clarke, N. (2007). Developing emotional intelligence through workplace learning: Findings from a case study in healthcare. Human Resource Development International, 9(4), 447-465.

Colley, H. (2012). Not learning in the workplace: Austerity and the shattering of illusio in public service work. Journal of Workplace Learning, 24(5), 317-337.

Cripps Clark, J., \& Groves, S. (2012). Teaching primary science: Emotions, identity and the use of practical activities. The Australian Educational Researcher, 39(4), 463-475.

Damasio, A. R. (1999). The feeling of happiness: Body and emotion in the making of consciousness. Orlando: Harcourt.

Dolev, N., \& Leshem, S. (2016). Teachers' emotional intelligence: The impact of training. The International Journal of Emotional Education, 8(1), 75-94.

Ekman, P. (2016). What scientists who study emotion agree about. Perspectives on Psychological Science, 11(1), 31-34.

Engeström, Y., Miettinen, R., \& Punamäki, R.-L. (1999). Perspectives on activity theory. Cambridge: Cambridge University Press.

Eraut, M. (2004). Informal learning in the workplace. Studies in Continuing Education, 26(2), 247-273.

Eraut, M. (2011). How researching learning at work can lead to tools for enhancing learning. In M. Malloch, L. Cairns, L. Evans, \& B. O'Connor (Eds.), SAGE handbook of workplace learning (pp. 181-197). London: Sage.

Eteläpelto, A., Vähäsantanen, K., Hökkä, P., \& Paloniemi, S. (2014). Identity and agency in professional learning. In S. Billett, C. Harteis and H. Gruber (Eds.), International Handbook of Research in Professional and Practice-based Learning. Vol.2. Dordrecht: Springer, 645-672.

Eteläpelto, A., Kykyri, V-L., Penttonen, M., Hökkä, P., Paloniemi, S., Vähäsantanen, K., Eteläpelto, T., \& Lappalainen, V. (2018). A multi-componential methodology for exploring emotions in learning. Frontline Learning Research, 6(3), 6-36.

Falkenström, E., Ohlsson, J., \& Höglund, A. T. (2016). Developing ethical competence in healthcare management. Journal of Workplace Learning, 28(1), 17-32.

Feldman Barrett, L. (1998). Discrete emotions or dimensions? The role of valence focus and arousal focus. Cognition and Emotion, 12(4), 579-599.

Fotaki, M., Kenny, K., \& Vachhani, S. J. (2017). Thinking critically about affect in organization studies: Why it matters. Organization, 24(1), 3-17.

Frijda, N. H., Manstead, A. S. R., \& Bem, S. (2000). Emotions and beliefs: How feelings influence thoughts. Cambridge: Cambridge University Press.

Gabriel, Y., \& Griffiths, D. S. (2002). Emotion, learning and organizing. The Learning Organization, 9(5), 214-221.

Geijsel, F., \& Meijers, F. (2005). Identity learning: The core process of educational change. Educational Studies, 31(4), 419-430.

Goleman, D. (1995). Emotional intelligence. New York: Bantam Books.

Goller, M., \& Paloniemi, S. (2017). Agency at work: An agentic perspective on professional learning and development. Cham: Springer.

Goller, M., Steffen, B., \& Harteis, C. (2018). Becoming a nurse aide: An investigation of an existing workplace curriculum in a nursing home. Vocations and Learning.

Gooty, J., Connelly, S., Griffith, J., \& Gupta, A. (2010). Leadership, affect and emotions: A state of the science review. The Leadership Quarterly, 21, 979-1004.

Grandey, A. A. (2000). Emotion regulation in the workplace: A new way to conceptualize emotional labor. Journal of Occupational Health Psychology, 5(1), 95-110.

Grandey, A. A. (2003). When "the show must go on": Surface acting and deep acting as determinants of emotional exhaustion and peer-rated service delivery. Academy of Management Journal, 46(1), 86-96.

Gross, J. (1998). The emerging field of emotion regulation: An integrative review. Review of General Psychology, 2(3), 271-299. 
Hareli, S., Shomrat, N., \& Biger, N. (2005). The role of emotions in employees' explanations for failure in the workplace. Journal of Managerial Psychology, 20(8), 663-680.

Hareli, S., Rafaeli, A., \& Parkinson, B. (2008). Emotions as social entities: Interpersonal functions and effects of emotion in organizations. In N. M. Ashkanasy \& C. L. Cooper (Eds.), Research companion to emotion in organizations (pp. 349-359). Northampton, MA: Edward Elgar.

Harmon-Jones, C., Bastian, B., \& Harmon-Jones, E. (2016). The discrete emotions questionnaire: A new tool for measuring state self-reported emotions. PLoS One, 11(8), 1-25.

Hastings, S. L. (2010). Triangulation. In N. J. Salkind (Ed.), Encyclopedia of research design (pp. 15381541). Thousand Oaks: Sage.

Hochschild, A. R. (1979). Emotion work, feeling rules, and social structure. American Journal of Sociology, $85(3), 551-575$.

Hochschild, A. R. (1983). The managed heart. Berkeley, CA: University of California Press.

Jakhelln, R. (2010). Early career teachers' emotional experiences and development: A Norwegian case study. Professional Development in Education, 37(2), 275-290.

Jokikokko, K., \& Uitto, M. (2016). The significance of emotions in Finnish teachers' stories about their intercultural learning. Pedagogy, Culture and Society, 25(1), 15-29.

Jr Reio, T., \& Callahan, J. (2004). Affect, curiosity, and socialization-related learning: A path analysis of antecedents to job performance. Journal of Business and Psychology, 19(1), 3-22.

Lave, J., \& Wenger, E. (1991). Situated learning: Legitimate peripheral participation. Cambridge: Cambridge University Press.

Lehtinen, E., Hakkarainen, K., \& Palonen, T. (2014). Understanding learning for the professions: How theories of learning explain coping with rapid change. In S. Billett, C. Harteis, \& H. Gruber (Eds.) International handbook of research in professional and practice-based learning, (pp. 199-224). Springer International Handbooks of Education. Vol. 1. Dordrecht: Springer.

Manuti, A., Pastore, S., Scardigno, A. F., Giancaspro, M. L., \& Morciano, D. (2015). Formal and informal learning in the workplace: A research review. International Journal of Training and Development, 19(1), 1-17.

McNally, J., Blake, A., \& Reid, A. (2009). The informal learning of new teachers in school. Journal of Workplace Learning, 2(4), 322-333.

Meijers, F. (2002). Career learning in a changing world: The role of emotions. International Journal for the Advancement of Counselling, 24(3), 149-167.

Mirchandani, K. (2012). Learning racial hierarchies: Communication skills training in transnational customer service work. Journal of Workplace Learning, 24(5), 338-350.

Morris, J. A., \& Feldman, D. C. (1997). Managing emotions in the workplace. Journal of Managerial Issues, 9(3), 257-274.

Nesbit, P. (2012). The role of self-reflection, emotional management of feedback, and self-regulation processes in self-directed leadership development. Human Resource Development Review, 11(2), 203-226.

Owen, S. (2016). Professional learning communities: Building skills, reinvigorating the passion, and nurturing teacher wellbeing and "flourishing" within significantly innovative schooling contexts. Educational Review, 68(4), 403-419.

Parkinson, B., Fischer, A. H., \& Manstead, A. R. (2005). Emotion in social relations: Cultural, group, and interpersonal processes. New York: Psychology Press.

Pradhan, R., Jena, L., \& Singh, S. (2017). Examining the role of emotional intelligence between organizational learning and adaptive performance in Indian manufacturing industries. Journal of Workplace Learning, 29(3), 235-247.

Rager, K. (2013). I feel, therefore, I learn: The role of emotion in self-directed learning. New Horizons in Adult Education and Human Resource Development, 23(2), 22-33.

Raemdonck, I., Thijssen, J., \& de Greef, M. (2017). Self-directedness in work-related learning processes: Theoretical perspectives and development of a measurement instrument. In M. Goller \& S. Paloniemi (Eds.), Agency at work: An agentic perspective on professional learning and development. Vol. 20. Cham: Springer, 401-423.

Rausch, A., Schley, T., \& Warwas, J. (2015). Problem solving in everyday office work: A diary study on differences between experts and novices. International Journal of Lifelong Education, 34(4), 448-467.

Rausch, A., Seifried, J., \& Harteis, C. (2017). Emotions, coping and learning in error situations in the workplace. Journal of Workplace Learning, 29(5), 374-393.

Riforgiate, S. E., \& Komarova, M. (2017). Emotion and work. The International Encyclopedia of Organizational Communication.

Russell, J. A. (1980). A circumplex model of affect. Journal of Personality and Social Psychology, 39(6), 1161-1178.

Russell, J. A. (2003). Core affect and the psychological construction of emotion. Psychological Review, 110(1), 145-172. 
Salovey, P., \& Mayer, J. (1990). Emotional intelligence. Imagination, Cognition and Personality, 9, $185-221$.

Sargeant, J., Mann, K., Sinclair, D., Van der Vleuten, C., \& Metsemakers, J. (2008). Understanding the influence of emotions and reflection upon multi-source feedback acceptance and use. Advances in Health Sciences Education, 13(3), 275-288.

Saunders, R. (2012). The role of teacher emotions in change: Experiences, patterns and implications for professional development. Journal of Educational Change, 14(3), 303-333.

Scherer, K. R. (1999). Appraisal theory. In T. Dalgleish \& M. J. Power (Eds.), Handbook of cognition and emotion (pp. 637-663). Chichester: Wiley.

Schreier, M. (2012). Qualitative content analysis in practice. London: Sage.

Scott, C., \& Sutton, R. (2008). Emotions and change during professional development for teachers: A mixed methods study. Journal of Mixed Methods Research, 3(2), 151-171.

Sebrant, U. (2008). The impact of emotion and power relations on workplace learning. Studies in the Education of Adults, 40(2), 192-206.

Seymour, D., \& Sandiford, P. (2005). Learning emotion rules in service organizations: Socialization and training in the UK public-house sector. Work, Employment and Society, 19(3), 547-564.

Shan, H. (2012). Learning to "fit in": The emotional work of Chinese immigrants in Canadian engineering workplaces. Journal of Workplace Learning, 24(5), 351-364.

Shepherd, D., Patzelt, H., \& Wolfe, M. (2011). Moving forward from project failure: Negative emotions, affective commitment, and learning from the experience. Academy of Management Journal, 54(6), 12291259.

Siltaloppi, M., Kinnunen, U., \& Feldt, T. (2009). Recovery experiences as moderators between psychosocial work characteristics and occupational well-being. Work and Stress, 23(4), 330-348.

Sutton, R. I., \& Rafaeli, A. (1988). Untangling the relationship between displayed emotions and organizational sales: The case of convenience stores. Academy of Management Journal, 31(3), 461-487.

Trehan, K., \& Rigg, C. (2015). Enacting critical learning: Power, politics and emotions at work. Studies in Higher Education, 40(5), 791-805.

Tynjälä, P. (2013). Toward a 3-P model of workplace learning: A literature review. Vocations and Learning, 6(1), 11-36.

Uitto, M., Jokikokko, K., \& Estola, E. (2015). Virtual special issue on teachers and emotions in teaching and teacher education (TATE) in 1985-2014. Teaching and Teacher Education, 50, 124-135.

Vähäsantanen, K. (2015). Professional agency in the stream of change: Understanding educational change and teachers' professional identities. Teaching and Teacher Education, 47, 1-12.

Vähäsantanen, K., Paloniemi, S., Hökkä, P. \& Eteläpelto, A. (2017). Agentic perspective on fostering workrelated learning. Studies in Continuing Education, 39(3), 251-267.

Valleala, U., Herranen, S., Collin, K., \& Paloniemi, S. (2015). Fostering learning opportunities through employee participation amid organizational change. Vocations and Learning, 8(1), 1-34.

Vince, R. (2002). The impact of emotion on organizational learning. Human Resource Development International, 5(1), 73-85.

Webb, S. (2012). Online tutoring and emotional labour in the private sector. Journal of Workplace Learning, 24(5), 365-388.

Wong, C. S., \& Law, K. S. (2002). The effects of leader and follower emotional intelligence on performance and attitude: An exploratory study. The Leadership Quarterly, 13(3), 243-274.

Zembylas, M. (2007). Theory and methodology in researching emotions in education. International Journal of Research and Method in Education, 30(1), 57-72.

Publisher's Note Springer Nature remains neutral with regard to jurisdictional claims in published maps

and institutional affiliations.

Päivi Hökkä , PhD, Adjunct Professor, is a senior researcher in education and adult education at the Department of Education, University of Jyväskylä. Hökkä is currently working on the REAL research project, which investigates emotions in agentic learning at work. She has recently conducted research and published articles on professional agency and identity, teacher education, emotions at work, and leadership in education. Her recent publications include articles for example in Journal of Teacher Education, International Journal of Leadership in Education, and Teaching and Teacher Education.

Katja Vähäsantanen, $\mathrm{PhD}$, Adjunct Professor, is a senior researcher at the Department of Education at the University of Jyväskylä, Finland. Vähäsantanen is currently working on the REAL research project, which investigates emotions in agentic learning at work. Her current research and teaching interests lie in the areas of 
professional identity, agency, learning, and emotions in work organisations. Her recent publications include articles in Vocations and Learning, Teaching and Teacher Education, Professional Development in Education, and Educational Research Review.

Susanna Paloniemi , PhD, is a senior researcher at the Department of Education, University of Jyväskylä. Paloniemi is currently working on the REAL research project. Her current research and teaching interests relate to professional learning, agency, and emotions in a variety of work contexts, as well as to the methodological approaches applicable to research on learning in working life. Her recent publications include articles in Professional Development in Education, Educational Research Review, and Management Learning. 